\title{
The Correlation between Emotional Intelligence and Project Management Success
}

\author{
Mounir El Khatib1, Mariam Almteiri², Shaikha Aysha Al Qasemi² \\ ${ }^{1}$ Hamdan Bin Mohammed Smart University, Dubai, United Arab Emirates \\ ${ }^{2}$ Graduate Project Management, Hamdan Bin Mohammed Smart University, Dubai, United Arab Emirates \\ Email: Drmunir.k@gmail.com
}

How to cite this paper: El Khatib, M., Almteiri, M., \& Al Qasemi, S. A. (2021). The Correlation between Emotional Intelligence and Project Management Success. iBusiness, 13, 18-29.

https://doi.org/10.4236/ib.2021.131002

Received: January 22, 2021

Accepted: February 22, 2021

Published: February 25, 2021

Copyright (c) 2021 by author(s) and Scientific Research Publishing Inc. This work is licensed under the Creative Commons Attribution International License (CC BY 4.0).

http://creativecommons.org/licenses/by/4.0/

(c) (i) Open Access

\begin{abstract}
As the number of projects increase in diverse fields, so the demand for effective project managers increases. In the United Arab Emirates, the recent exponential growth has resulted in increased projects. However, determining an individual who would make an effective project manager continues to be a challenge. In this study, the correlation between emotional intelligence and project success was explored. Initially, valuable secondary research was carried out to point out the main features a project manager with high Emotional Intelligence (EI) exhibits followed by proof of correlation between those features and an above average EI score. An online survey was administered to fifteen project managers to collect data concerning their emotional intelligence and the success of their projects. According to the findings, emotional intelligence correlates strongly with project success. Consequently, this study recommends that organizations should hire emotionally intelligent project managers to ensure project management success.
\end{abstract}

\section{Keywords}

Emotional Intelligence, Project Management, Management Success, Performance

\section{Introduction}

In this paper, we will initially cover the popular definitions of Emotional Intelligence in the workplace and enlist the components of Emotional intelligence relevant to project managers followed by a comparison between Emotionally intelligent project managers and project managers with high IQ but low EI with supporting examples from international companies. Finally, in the literature review, we cover a large scale and extensive research carried out in Malaysia mea- 
suring EI and carrying out interviews to find out whether emotional intelligence causes a change in the management styles. Primary research is finally carried on a modest sample in order to provide initial statistics about EI effects on project management in GCC countries that could be later expanded in future research.

Project management encompasses the application of skills, knowledge, procedures, and methodologies, and experience to attain the objectives of a project. As more private and public organizations undertake projects, the need for effective project managers increases. According to the Project Management Institute (n.d.), there is an increasing gap between the need for skilled project managers and the supply of qualified personnel. The main reasons for the increased demand for project managers include the high number of jobs that require job-oriented skills and high attrition rates in the industry (Project Management Institute, n.d.). Some of the leading sectors in need of project managers include manufacturing and construction, finance and insurance, information services and publishing, oil and gas, utilities, and management and professional services.

Several qualities have been identified as being essential to the project management role. Based on Ahmed (2013), they include self-awareness, tolerance, critical thinking, honesty, problem-solving, and decision-making. Other key attributes encompass people-oriented, visionary, effective communication, team building, and a trust builder (Ahmed, 2013). According to Montequin, Nieto, Ortega, and Villanueva (2015), the kind of leadership style a manager implements affects the success of a project. As a result, effective project managers tend to be exhibit rational judgement, extroversion, and structured behaviors (Montequin et al., 2015). Some researchers have also suggested that there is a link between project management and emotional intelligence (Obradovic, Jovanovic, Petrovic, Mihic, \& Mitrovic, 2013). However, scholarly literature in this field has been confined to countries other than the UAE. In this paper, the association between emotional intelligence and project management in the context of the UAE is examined in detail. The research questions of this paper are: how emotional intelligence affects project management and how to use emotional intelligence to improve project performance.

\section{Literature Review}

Emotional intelligence is a concept that continues to find applications in leadership studies. However, the scholarly society has failed to agree on a single definition mainly because emotional intelligence occurs in different contexts. Nevertheless, one of the most referenced definitions is the one advanced by Daniel Goleman (Hess \& Bacigalupo, 2013). Based on Goleman, emotional intelligence refers to an individual's capacity to recognize, feel, and deal with emotions (Hess \& Bacigalupo, 2013). The Goleman's model identified five components of emotional intelligence. The first one is self-awareness, which refers to the capability to identify and comprehend one's emotions, moods, and drives as well as the effects of these aspects on other people. According to Hess and Bacigalupo (2013), the hallmarks of self-awareness include realistic self-assessment and self-confidence. 
The second component of the model is self-regulation. As the name suggests, it refers to the capability to control moods and impulses. In practice, it entails having the ability to think before acting and avoiding judgement. According to Hess and Bacigalupo (2013), individuals with self-regulation demonstrate an openness to change or new ideas and combine comfort with ambiguity. They are also able to demonstrate integrity and trustworthiness (Afzalur Rahim et al., 2002). In the third component, Goleman identified motivation as another element of emotional intelligence. Based on Afzalur Rahim et al. (2002), motivation refers to the passion to work on something for reasons that go beyond status and monetary gain. It encompasses the capacity to pursue objectives with energy and in a persistent way. Individuals who are motivated exhibit a strong drive to achieve, remain optimistic even during times of failure, and are committed to their organizations.

The fourth component, empathy, refers to the capacity to comprehend the emotional status of others. Therefore, the empathy component stresses the importance of recognizing the feelings of other people and treating them based on their feelings. The key features of empathy include being sensitive to other cultures, being able to provide effective service to customers, and having the skill to build teams and retain talent (Hess \& Bacigalupo, 2013). The last one is the social skill component which refers to the ability to build networks and manage relationships (Hess \& Bacigalupo, 2013). An individual with effective social skills can build rapport and good relationships with others (Hess \& Bacigalupo, 2013). Effective social skills are evidenced by persuasion, change leadership, and exemplary team management.

The overarching view in research literature is that while intellectual intelligence is imperative to the attainment of high performance, emotional intelligence helps individuals to progress even further. According to Lahin (2016), individuals in high positions of leadership require emotional intelligence to help them function effectively. In particular, Lahin (2016) pointed out that emotional intelligence is essential in tasks that involve more interpersonal actions. Since project management entails leading a team and acting as a liaison between the project team and the sponsor, it can be categorized as an undertaking that involves intense interpersonal relationships. Consequently, based on Lahin (2016), effective project managers might require effective interpersonal skills as well.

In the study of the relationship between emotional intelligence and project management, it is important to explore the potential impact of communication and leadership. Effective communication is key to creating teams and influencing others towards the attainment of a given objective. In project management, change communication helps to create a shared meaning. To the team members, the project manager is required to communicate the need to prioritize tasks to ensure adherence to the schedule and budget (Ziek \& Anderson, 2015). Stakeholder management, which involves ensuring that the needs of every stakeholder are considered when implementing a project, is improved through effective communication. On its part, leadership is about influencing others towards the 
attainment of the project objectives. Increasingly, research literature has identified transformational leadership as the best style for project managers (Hassan, Bashir, \& Abbas, 2017). Essentially, transformational leadership is perceived as a style that produces change. Since project management is about change, transformational leadership is seen as an approach that allows a leader to ensure that everyone in the team is focused on attaining the desired change. Overall, communication and leadership are associated with the concept of emotional intelligence and can help to determine whether emotional intelligence is related to effective project management.

Another definition for emotional intelligence as stated in an article by Casper (2002) states that emotional intelligence is the ability to sense, understand, manage and apply the information and power of emotions as your greatest source of energy, motivation, connection and influence. Research shows that teams that attain and sustain high performance have a high Emotional Intelligence Quotient (EQ) and has been a constant source of team success. An emotionally intelligent team creates the perfect work dynamic in which workplace conflict is kept to a minimum, suggestions are invited and taken when considered effective and everyone is aware of their roles and responsibility and is motivated to maximize their output. A research in Bell labs, New Jersey attempted to find the main reason behind the success of their "star performers" and after a series of studies the one factor that was found to be a common trait of these project managers was their ability to effectively use EI to build networks to problem solve and create.

The same article published in the Project Management Institute (2002) also goes to the extent of marking EI as more important than IQ for the project management role for the following reasons. A person with low EI performs poorly in the management role due to exhibiting behavior that hinders project progress and success such as offending team members and being sarcastic causing them to become less productive, gets defensive easily which is a main cause of conflict instigation hindering the project even further and therefore cannot build healthy and effective work relationships, cannot adapt quickly during times of change or even communicate effectively with stakeholders despite being a practical genius when it comes to IQ scores. On the other hand, people that rated high in emotional intelligence exhibited behavior that accelerated project progress and powerfully utilized relationships with colleagues and stake holders such as being able to keep team members motivated throughout the duration of the project, increasing shareholder value through establishing trust and leveraging relationships in order to create breakthrough strategies, ability to transform conflicts and mishaps into opportunities and the ability to produce a high quality deliverable on time, on budget without the tapping into the highly stressful environment and exhausting all resources.

In order to further highlight importance of emotional intelligence in the role of project management, an article published on PM PrepCast (n.d.) which is a website with a purpose of preparing future project managers for their profes- 
sional project management (PMP) certification elaborates on how emotional intelligence is embedded into areas of project management beyond just human resources. Some high level examples of this correlation would be areas such as scope management, in which individuals with higher emotional intelligence are less likely to sign off a project scope to a process they are unable to put up with and are less likely to be pressured by the situation or surroundings to give false promises or exaggerated deliverables. Another important aspect of project management which calls for high emotional intelligence would be risk management. Facing risk is another stress creator in the workplace which often creates conflict and a lack of consensus. This issue poses less of a threat once the project manager rates high in EQ in which he is more able to prioritize risks and get all the team members on board.

After stating all the benefits associated with high EI and EQ, it remains important that we provide solid proof of the benefits previously discussed being strictly correlated high EQ. An article published in the Journal of Management in Engineering by Sunindijo et al. (2007) carried a large scale study in Bangkok in which a sample of 22 project managers, and 12 project engineers were first made to take an EQ test and then interviewed on their leadership skills and use of emotions in the workplace. The study has made 2 very important conclusions, the first being that the EQ average of all the participants was in fact equal to the average of the population (approximately 14,000 participants at the time) which was 75 . The second conclusion made was based on a study which proved that after separating participants into 2 groups, those with scores above average and those below, it was found that that participants with an EI score above average were bigger advocates of open communication, listening, participating, and proactive behavior more than the PMEs with lower EI scores.

\section{Emotional Intelligence in the UAE}

Since the UAE is undertaking mega projects, especially in Dubai and Abu Dhabi, the need for project managers has increased drastically. One research paper with the title

"Emotional Intelligence and Demographic Profile Variables as Predictors of Job Performance among Bank Managers in the Middle East" examined the relationship between emotional intelligence and the success of project managers. The findings were that bank managers in the middle east that have been performing well have very high emotional intelligence. It also mentioned that since bank managers are required to deal with customers, therefore, having high emotional intelligence will allow one to increase customer satisfaction which in return allows them to perform greatly on their job, thus emphasizing the positive correlation of Emotional Intelligence and Project management success (Bajpai, 2013). Another research that was made in the UAE which also emphasized the importance of Emotional Intelligence to project management success was present in a CSR initiative called Happiness talks where a talk was given by an 
emotional intelligence consultant Nasreen Kawash, where she highlighted the new science of emotions and the brain, as well as neuroscience and positive psychology that rely on strengthening our emotional intelligence that helps one to develop, grow and implant a positive mindset, which in return helps one to better themselves, and build relationships with others and influence others ( $\mathrm{Ha}-$ ziq, 2017).

\section{Research Methodology}

For our research, we attempted both quantitative and qualitative approaches. The primary research examines the relationship between emotional intelligence and project management and success. The first step in the research would be to select the research sample. In our case, the respondents were project managers that work in different project environments drawn from the numerous departments under Emirates airlines group of companies in the UAE. The sampling technique that would be utilized is the snowball sampling method as it would help to find respondents. Since project managers are few, the snowball method is the ideal approach. In this technique, the researcher selects respondents by finding one or two individuals and then requesting them to refer him or her to others. Therefore, the researcher will find one or two project managers and ask them to refer him to other project managers. Although this approach allows one to access the right sample, its main drawback is that the sample selected is likely to be biased. In other words, the representatives of the sample may be low. Nevertheless, this approach would be used as project managers can be viewed as a homogenous population. In total, we intended to obtain a sample population of twenty respondents.

Once the required number of participants were attained, the project manager we contacted, forwarded the questionnaire that was done through an online platform referred to as Survey Monkey to other project managers in Emirates airlines working in the different departments to other project managers in the different departments of Emirates airlines. The use of this platform is important as it allows for an easy collection of data through its in-built templates. The questionnaire was composed of three parts. The first part collected the respondent's personal information such as age, educational qualification, gender, and years of experience.

The second part was composed of questions drawn from an emotional intelligence scale. The Wong and Law Emotional Intelligence Scale (WLEIS), which was composed of sixteen items that assess the respondents' emotional intelligence (Libbrecht, Lievens, \& Schollaert, 2010). The sixteen items are categorized into four domains with each domain having four items. The domains include self-appraisal, emotional regulation, utilizing emotion, and an individual's appraisal of other people (Libbrecht, Lievens, \& Schollaert, 2010). To use of a scale that has been tested for reliability and validity is essential as it enhances the credibility of the findings. In this study, only four items-instead of the sixteen-were 
utilized.

The final part collected data concerning each respondent's performance in previous projects. It will contain eight items on a Likert scale measuring critical areas that determine the success of a project. Those areas include the budget, timelines, standards, technical specifications, executive management support, effective communication, project objectives, and controlling and monitoring of projects. There was also a qualitative question in which a respondent was required to explore the relationship between emotional intelligence and project success. ${ }^{1}$

\section{Findings}

All the fifteen questionnaires were filled correctly. Based on the demographics, the ages of the respondents ranged from 30 to 55, all of them had college degrees, their years of experience ranged from 5 to 20 , and ten were male while five were female. Based on the Likert scale, strongly disagree corresponded to 1 and strongly agree corresponded to 5 . Since there are four items, the maximum score a respondent can obtain is 20 and the minimum score is 4 . In contrast, since the project success scale has eight items, the maximum score is 40 and the minimum is 8 . The results are summarized in Table 1 below. Based on the results, the average emotional intelligence score for the fifteen respondents was 17.23, which means that they rate themselves highly in terms of their emotional intelligence capability. On the other hand, the average score for project success was 31.7, which also denotes a considerably high success rate.

A correlation analysis was performed to determine whether a correlation exists between emotional intelligence and project success. Based on the results, the correlation coefficient ( $r$ ) was found to be 0.744 . Essentially, a positive correlation means that an increase in the independent variable results in an increase in the dependent variable as well. Additionally, since correlation ranges from +1 to

Table 1. Total scores for each participant (emotional intelligence [EI] and project success).

\begin{tabular}{cccc}
\hline EI & Project Success & EI & Project Success \\
\hline 20 & 35 & 20 & 30 \\
14 & 28 & 16 & 33 \\
15 & 30 & 17 & 34 \\
17 & 33 & 19 & 34 \\
14 & 26 & 18 & 35 \\
19 & 33 & 20 & 36 \\
18 & 32 & 15 & 27 \\
17 & 30 & & Avg $=31.7$ \\
\hline
\end{tabular}

${ }^{1}$ Questionnaire in Appendix. 
-1 , a value close to +1 indicates a strong correlation. Therefore, the value of $r=$ 0.744 means that there is a strong correlation between emotional intelligence and project success. It is important, however, to understand that correlation does not mean causation. Overall, it is evident that emotional intelligence is correlates with project success.

The final question, which adopted a qualitative approach, was aimed at collecting the respondents' views regarding the potential link between emotional intelligence and project success. According to the responses, several themes emerged: emotional intelligence supports communication and teamwork; emotional intelligence enhances stakeholder management; and emotional intelligence enhances the top management's support for the project. More importantly, the respondents argued that there is a relationship between emotional intelligence and effective leadership, which directly influences the success of change initiatives.

\section{Suggestions/Recommendations}

The results of the study confirm that a project manager's emotional intelligence positively correlates with the likelihood of a project succeeding. Therefore, it is important for organizations to hire project managers with high levels of emotional intelligence. Based on the emotional intelligence scale utilized, an emotionally intelligent person is one who can assess and express his or her emotions; can recognize other people's emotions; can manage his or her own feelings and emotions; and can use emotion in work settings to facilitate performance (Libbrecht, Lievens, \& Schollaert, 2010). Therefore, project managers should know their emotions. Essentially, it is only through the understanding of one's self that one can know how to behave or act in the presence of others.

The project manager should have the capability of self-management, which encompasses having a positive outlook, being adaptable, having control of emotions, and being oriented towards achievement. Adaptability is particularly important in project management settings as things do not often go as planned (Quisenberry, 2018). Factors within the organization and those outside of it can influence the course of a project. For example, the enactment of new government regulations forces a project manager to conform, which might encompass having to implement a contingency plan. Emotional intelligence also allows one to have a positive outlook and motivate others towards the envisaged outcome, even during times of challenges.

Social awareness, which is a dimension of emotional intelligence, enables one to have empathy and a good organizational understanding. A critical feature of effective project managers is that they have a good knowledge of the internal capabilities and weaknesses. This knowledge is important when executing a project. For example, if an organization has an exemplary workforce, then the project manager can rely on it in idea generation and implementation. Furthermore, emotional intelligence supports effective relationship management, that 
includes teamwork and conflict management. At the heart of project management is collaboration. Essentially, the project manager should be able to create a culture that supports teamwork and innovation, and emotional intelligence helps him or her to attain that.

The respondents also identified communication, leadership, and top management commitment as some of the key factors that determine the success of a project. At the same time, emotional intelligence supports these three factors. Communication can be perceived as a tool that allows the project manager to communicate the vision and progress of a project. Effective communication is important as it helps to build partnerships. When a project idea is communicated well, it is likely to receive the support of diverse stakeholder groups. Similarly, effective leadership ensures that the project manager can steer the project towards the intended outcome. The transformational leadership style, which is supported by emotional intelligence, helps to create an atmosphere of change (Kim \& Kim, 2017). Project managers, as transformational leaders, possess the ability to solicit for ideas, learn from past mistakes, pursue innovation, and ensure sustainable progress that is characterized by sessions of celebrating and re-energizing. Executive management buy-in is essential in project management as it determines the level of funding and prioritization that a project would receive. Similarly, an emotionally intelligent project manager can package and communicate the benefits of the project and, therefore, earn the commitment of the top management.

Moreover, recommendations for organizations should include emotional intelligence tests in the hiring and recruitment process of project managers with a certain level or pass or fail. This will increase the awareness of the importance of emotional intelligence. Also, activities should be held within an organization that increases the emotional intelligence of a person and the team work.

\section{Conclusion}

Emotional intelligence and project success are positively correlated. The key attributes of emotional intelligence include self-awareness, the capability to regulate emotions, motivation, possession of social skills, and empathy. An emotionally intelligent person can understand his or her emotions and control them while remaining motivated. $\mathrm{He}$ or she should have the capacity to understand the emotions of others and manage relationships effectively. By its very nature, project management entails implementing change. Often, employees and other stakeholders might resist the change or fail to give it the required support. Therefore, having an emotionally intelligent manager is imperative as he or she can anticipate any issues and address them. Emotional intelligence also enhances the communication and leadership capabilities of the individual. Overall, the study recommends that organizations should include emotional intelligence in the hiring and recruitment processes of project managers.

The main limitation of this study is that it utilizes a relatively small number of 
respondents due to the schedules of the project managers and the limited contact due to precautions and measures taken. Due to COVID-19, the information was collected through essays rather than extensive interviews in person. Essentially, the accuracy of findings is enhanced when the number of participants is sufficiently large. Consequently, future studies should attempt to rely on a bigger number of research respondents. The second limitation is that the snowball sampling method was utilized, which reduced the representativeness of the sample. Lastly, the study was limited to the context of the UAE. As a result, it is difficult to generalize the findings to other countries.

Given the discussed limitations, a large scale study should be carried out similar to the one previously discussed in the literature review in which a massive number of respondents is acquired to calculate an average EI that represents the GCC region and then conduct detailed interviews with both parties above and below average to spot the main difference in management styles and success that could be related to EI.

\section{Conflicts of Interest}

The authors declare no conflicts of interest regarding the publication of this paper.

\section{References}

Afzalur Rahim, M., Psenicka, C., Polychroniou, P., Zhao, J. H., Yu, C. S., Anita Chan, K. et al. (2002). A Model of Emotional Intelligence and Conflict Management Strategies: A Study in Seven Countries. The International Journal of Organizational Analysis, 10, 302-326. https://doi.org/10.1108/eb028955

Ahmed, R. (2013). Qualities of Project Manager. https://www.researchgate.net/publication/276414112_QUALITIES_OF_PROJECT_M ANAGER

Bajpai, S. (2013). Higher Emotional Intelligence Makes You a Better Leader. GulfNews. https://gulfnews.com/uae/education/higher-emotional-intelligence-makes-you-a-better -leader-1.1213707

Casper, C. M. (2002). Using Emotional Intelligence to Improve Project Performance. Paper Presented at Project Management Institute Annual Seminars \& Symposium, San Antonio, TX. Newtown Square, PA: Project Management Institute.

Hassan, M. M., Bashir, S., \& Abbas, S. M. (2017). The Impact of Project Managers' Personality on Project Success in NGOs: The Mediating Role of Transformational Leadership. Project Management Journal, 48, 74-87. https://doi.org/10.1177/875697281704800206

Haziq, S. (2017). Happiness Linked to Emotional Intelligence: Experts. Khaleej Times. https://www.khaleejtimes.com/nation/dubai/happiness-linked-to-emotional-intelligenc e-experts

Hess, J. D., \& Bacigalupo, A. C. (2013). Applying Emotional Intelligence Skills to Leadership and Decision Making in Non-Profit Organizations. Administrative Sciences, 3, 202-220. https://doi.org/10.3390/admsci3040202

Kim, H., \& Kim, T. (2017). Emotional Intelligence and Transformational Leadership: A Review of Empirical Studies. Human Resource Development Review, 16, 377-393. 
https://doi.org/10.1177/1534484317729262

Lahin, D. (2016). Better Project Management through Better Emotional Intelligence. PM World Journal, 5, 1-10.

Libbrecht, N., Lievens, F., \& Schollaert, E. (2010). Measurement Equivalence of the Wong and Law Emotional Intelligence Scale across Self and Other Ratings. Educational and Psychological Measurement, 70, 1007-1020. https://doi.org/10.1177/0013164410378090

Montequin, V. R., Nieto, A. G., Ortega, F., \& Villanueva, J. (2015). Managerial Style Profiles of Successful Project Managers: A Survey. Procedia Computer Science, 64, 55-62. https://doi.org/10.1016/j.procs.2015.08.463

Obradovic, V., Jovanovic, P., Petrovic, D., Mihic, M., \& Mitrovic, Z. (2013). Project Managers' Emotional Intelligence-A Ticket to Success. Procedia-Social and Behavioral Sciences, 74, 274-284. https://doi.org/10.1016/j.sbspro.2013.03.034

PM PrepCast (n.d.). Emotional Intelligence and Project Management. https://www.project-management-prepcast.com/free/pmp-exam/articles/882-emotiona l-intelligence-and-project-management2

Project Management Institute (n.d.). Project Management: Job Growth and Talent Gap (2017-2027). PMI.

https://www.pmi.org/-/media/pmi/documents/public/pdf/learning/job-growth-report. pdf

Quisenberry, W. L. (2018). Exploring How Emotional Intelligence Contributes to Virtual Teams: Interpretive Analysis of a Phenomenological Study. European Scientific Journal, 14, 19-39. https://doi.org/10.19044/esj.2018.v14n5p19

Sunindijo, R., Hadikusumo, B., \& Ogunlana, S. (2007). Emotional Intelligence and Leadership Styles in Construction Project Management. Journal of Management in Engineering, 23.

https://ascelibrary.org/doi/full/10.1061/\%28ASCE\%290742-597X\%282007\%2923\%3A4 \%28166\%29? casa_token=56y5zqO6EDUAAAAA\%3A7-wvf5E1QiNB1v-zQ4dEmtiZK UuIzOIUrMYT0YxEPAmi0Hwc7g_DimRUlZWQQF927lmsvWjTY8Q https://doi.org/10.1061/(ASCE)0742-597X(2007)23:4(166)

Ziek, P., \& Anderson, J. D. (2015). Communication, Dialogue and Project Management. International Journal of Managing Projects in Business, 8, 788-803.

https://doi.org/10.1108/IJMPB-04-2014-0034 


\section{Appendix}

\section{Questionnaire}

\section{Personal Information}

Name:

Age:

Educational qualification:

Gender:

Years of experience:

Emotional Intelligence

\begin{tabular}{|c|c|c|c|c|c|}
\hline & $\begin{array}{l}\text { Strongly } \\
\text { disagree }\end{array}$ & Disagree & Neutral & Agree & $\begin{array}{c}\text { Strongly } \\
\text { agree }\end{array}$ \\
\hline \multicolumn{6}{|l|}{$\begin{array}{l}\text { I am aware of my own emotions and } \\
\text { can explain them to others. }\end{array}$} \\
\hline \multicolumn{6}{|l|}{ I can regulate or manage my emotions. } \\
\hline \multicolumn{6}{|l|}{$\begin{array}{l}\text { For example, if I am frustrated, I can } \\
\text { overcome the frustration. }\end{array}$} \\
\hline \multicolumn{6}{|l|}{ I can use my emotions appropriately. } \\
\hline $\begin{array}{l}\text { I possess the capability to read other } \\
\text { people's emotions or feelings. }\end{array}$ & & & & & \\
\hline
\end{tabular}

\section{Project Success}

Strongly
disagree Disagree Neutral Agree $\begin{gathered}\text { Strongly } \\ \text { agree }\end{gathered}$

Project are always completed within the budget

Project are always completed within the required timelines

Project always meet the quality standards set.

Project always meet the technical specifications.

Projects always get total support from the top management

Effective communication practices are usually adopted in the projects.

The goals and objectives of the projects are usually well-defined

Controlling and monitoring projects is always done effectively.

Do you think that emotional intelligence influences the success of a project? If so, please elaborate. 